\title{
The Potential for the Formation of Sclerotia in Submerged Mycelium of Sclerotium rolfsii
}

\author{
By Y. HADAR, Y. HENIS* AND I. CHET \\ Department of Plant Pathology and Microbiology, Faculty of Agriculture, The Hebrew \\ University of Jerusalem, Rehovot, Israel
}

(Received 8 February 1980; revised 15 May 1980)

Synchronous formation of sclerotia in Sclerotium rolfsii was induced in both solid and liquid synthetic media. Sclerotial initials were formed when mycelium was forced to pass from the submerged to the aerial growth phase in one of the following ways: (i) by removal of aerial mycelium with a scalpel; (ii) by growing the mycelium under a cover glass which was later removed; (iii) by inverting the agar in a Petri dish containing the fungal culture; (iv) by pouring a layer of agar over a colony. In all cases hyphae which emerged from the submerged phase produced many sclerotia synchronously. When grown in shaken liquid culture $S$. rolfsii did not produce any sclerotia while submerged, but when samples of the shaken culture were poured into a Petri dish 50 to $90 \mathrm{~h}$ after inoculation and incubated further, sclerotial initials were formed synchronously within $16 \mathrm{~h}$ on the liquid surface.

\section{INTRODUCTION}

When grown on an agar medium Sclerotium rolfsii Sacc. forms a submerged vegetative mycelium consisting of single hyphae and an aerial mycelium composed of both single hyphae and hyphal strands. Sclerotial initials are formed on these hyphal strands (Townsend \& Willetts, 1954). Sclerotium formation on agar plates usually occurs when the mycelium approaches the edge of the Petri dish (Wheeler \& Waller, 1965); it can also be induced by cutting the mycelium with a cork borer (Henis et al., 1965). Synchronization of sclerotium formation can be induced by the addition to the growth medium of iodoacetic acid (Chet $e t$ al., 1966), lactose (Okon et al., 1972) or threonine (Kritzman et al., 1976).

When grown in liquid medium $S$. rolfsii produces an extracellular viscous polysaccharide (Kritzman et al., 1979) but does not produce any sclerotia (Okon et al., 1974). In this paper we report on the development of a sclerotium-producing potential in the submerged mycelium of $S$. rolfsii which can be revealed when mycelial growth is transferred from a submerged to an aerial environment.

\section{METHODS}

Strain and growth conditions. Sclerotium rolfsii type A ATCC 26325 (Chet \& Henis, 1972) was grown at $30^{\circ} \mathrm{C}$ either on an agar medium in Petri dishes or in Erlenmeyer flasks containing liquid synthetic medium (Okon et al., 1973). Plates containing $15 \mathrm{ml}$ solidified medium were centrally inoculated with agar discs $(0.5 \mathrm{~cm}$ diam.) covered with fungal mycelium which had been cut from a $5 \mathrm{~d}$ colony. Flasks containing $50 \mathrm{ml}$ medium were inoculated with $1 \mathrm{ml}$ suspension containing $10 \mathrm{mg}$ (dry wt) mycelium and incubated at $30^{\circ} \mathrm{C}$ in a rotary shaker (New Brunswick Scientific) at $150 \mathrm{rev} \cdot \mathrm{min}^{-1}$ for $3 \mathrm{~d}$. Inoculum was prepared by homogenizing mycelium in the culture flask with an Ultra-Turrax homogenizer (Janke \& Kunkel KG., West Germany) operated at one-third of maximum speed (Zweck et al., 1978).

Analyses. Mycelium was separated from extracellular polysaccharide by centrifugation at $12000 \mathrm{~g}$ for $20 \mathrm{~min}$ at $4{ }^{\circ} \mathrm{C}$. Polysaccharide was precipitated by mixing the supernatant with 2 vol. ethanol. The precipitate was collected on a glass rod, washed three times with cold ethanol, lyophilized and weighed. To determine dry weight, samples 
were dried at $70^{\circ} \mathrm{C}$ in an oven to constant weight. Glucose was determined using the glucose oxidase reagent (Sigma) according to the directions of the manufacturer.

\section{RESULTS}

\section{Induction of synchronous sclerotium production by transition from submerged to aerial growth}

When the aerial mycelium of Sclerotium rolfsii grown on agar was removed with a scalpel, the hyphae rising from the submerged mycelium simultaneously produced sclerotial initials within $16 \mathrm{~h}$ (Fig. 1). The response of $S$. rolfsii to removal of its aerial mycelium depended both on the age of the colony and on the agar concentration. Highest numbers of sclerotia were produced in a medium containing $4 \%(\mathrm{w} / \mathrm{v})$ agar (Fig. 2). For all the agar concentrations tested the maximum production of sclerotial initials occurred when the aerial mycelium was removed 3 to $4 \mathrm{~h}$ prior to sclerotial initiation in the control. Earliest initiation appeared in the area of a $64 \mathrm{~h}$ colony from which aerial mycelium had been removed at $48 \mathrm{~h}$. Numbers of initials formed in the treated colony area increased with colony age. However, removing aerial mycelium which had already formed sclerotial initials resulted in a reduced number of new initials. Moreover, a second removal of newly formed aerial mycelium and initials from a previously treated area did not result in sclerotium formation, indicating that the same area of a $S$. rolfsii colony could not produce sclerotia twice.

According to Wheeler \& Waller (1965), untreated colonies of $S$. rolfsii do not produce sclerotial initials until the mycelium approaches the edge of the Petri dish regardless of the size of dish used. In our system, however, removing the aerial mycelium from a colony grown in a $15 \mathrm{~cm}$ diam. Petri dish $64 \mathrm{~h}$ after inoculation resulted in the production of large numbers of initials, although the untreated parallel area of the same thallus had not yet produced any initials (Fig. $1 b$ ). Thus, the removal of aerial mycelium of $S$. rolfsii revealed the potential for production of sclerotia long before fungal growth had reached the edge of the Petri dish.

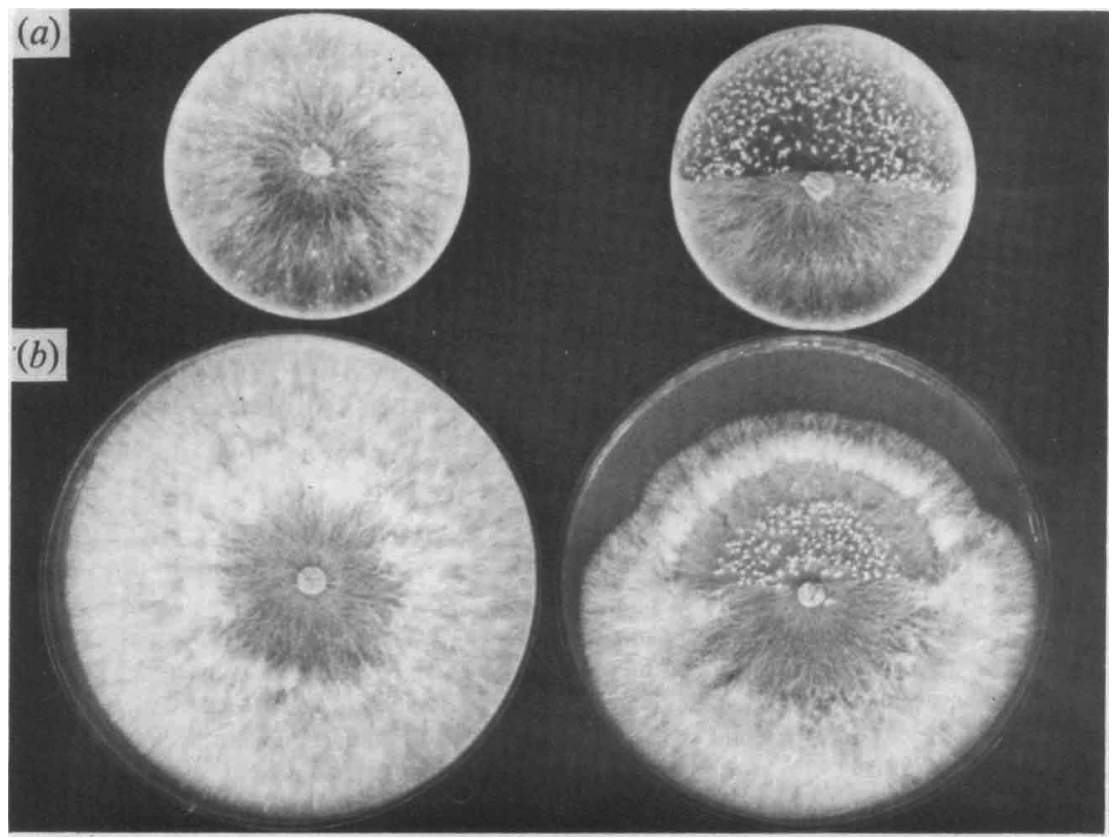

Fig. 1. Synchronous sclerotium formation as a result of removal of aerial mycelium of Sclerotium rolfsii $72 \mathrm{~h}$ after inoculation in $9 \mathrm{~cm}(a)$ and $15 \mathrm{~cm}(b)$ diam. Petri dishes, photographed $24 \mathrm{~h}$ later (left, control; right, mycelium removed from half of the colony). 


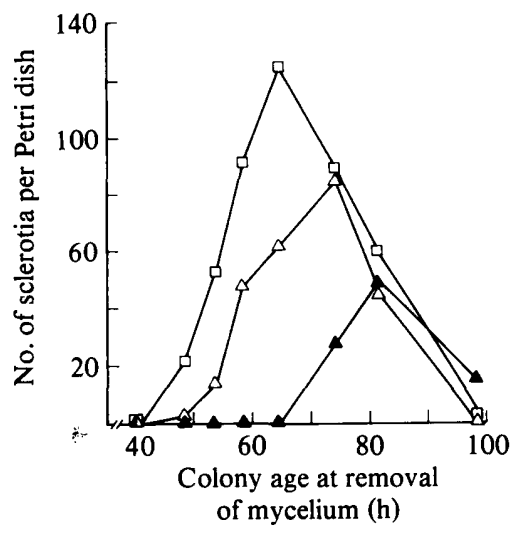

Fig. 2. Effect of removal of aerial mycelium on sclerotium formation by Sclerotium rolfsii as a function of colony age at different agar concentrations: $\triangle, 0.7 \% ; \Delta, 2 \% ; \square, 4 \%$.
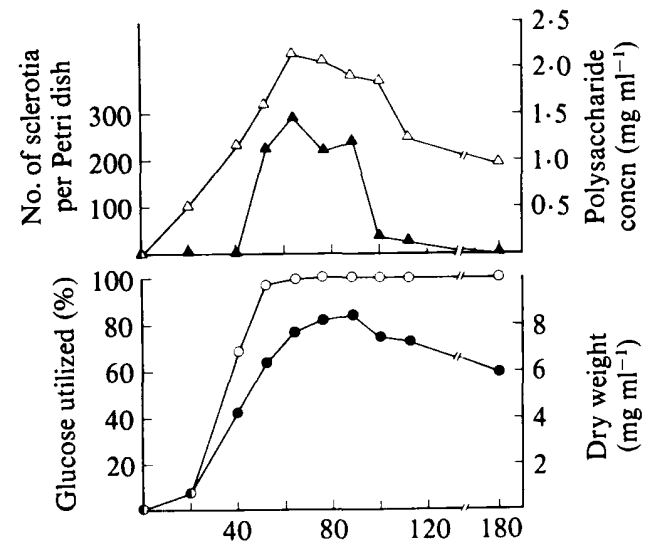

Culture age at transfer to stationary incubation $(\mathrm{h})$

Fig. 3. Sclerotium formation (A) by Sclerotium rolfsii $16 \mathrm{~h}$ after transfer from shaken to stationary incubation. Glucose utilization $(O)$, polysaccharide concentration $(\triangle)$ and dry weight $(O)$ at time of transfer are also shown.

To examine the possibility that induction of sclerotia might have resulted from mechanical damage (Henis et al., 1965), growth of aerial mycelium was prevented by covering the growing thallus with a cover glass placed at the edge of a $24 \mathrm{~h}$ colony. Under these conditions, the culture underneath the cover glass consisted of submerged mycelium only. Removal of the cover glass after $48 \mathrm{~h}$ was followed by an extensive outgrowth of new aerial mycelium, with the concomitant appearance of sclerotial initials. Removal of the cover glass either $24 \mathrm{~h}$ before or after the optimal time (i.e. $72 \mathrm{~h}$ ) did not result in the formation of any sclerotial initials.

Induction of sclerotia without damage to the mycelium was also achieved either by inverting the agar medium in Petri dishes containing $72 \mathrm{~h}$ colonies so that aerial mycelium came in contact with the bottom of the dish, or by pouring $10 \mathrm{ml}$ water agar over the culture surface and incubating further. Under these conditions new hyphae grew through the upper layer and produced initials on the surface within $24 \mathrm{~h}$.

\section{Capacity for sclerotium production of submerged liquid cultures}

When $S$. rolfsii was grown in a shaken liquid medium, no sclerotia were produced in the submerged culture (Okon et al., 1974). Moreover, when these flasks were transferred to 
stationary incubation within the first $40 \mathrm{~h}$ of shaking, the liquid surface became covered with vegetative mycelium only. Cultures transferred to stationary incubation after 50 to $90 \mathrm{~h}$ of shaking produced many sclerotial initials synchronously. Similar results were obtained when $15 \mathrm{ml}$ samples of the liquid cultures were poured into Petri dishes after the same period of shaking, and incubated for a further 12 to $16 \mathrm{~h}$. Production of fungal biomass (dry weight) and extracellular polysaccharide reached a plateau $52 \mathrm{~h}$ after inoculation, by which time most of the glucose had been utilized. The capacity for sclerotium production decreased $95 \mathrm{~h}$ after inoculation and at the same time there was a significant decrease in the polysaccharide content of the medium (Fig. 3).

\section{DISCUSSION}

Our results suggest that the submerged mycelium of Sclerotium rolfsii plays an active role in the regulation of sclerotium production. Synchronous formation of sclerotia could be triggered by changing the relative proportions of aerial and submerged mycelium in favour of the latter. Sclerotia are always produced on strands of aerial hyphae (Townsend \& Willetts, 1954) and never in submerged mycelium, whether growth is on solid or in liquid medium (Okon et al., 1976), in accord with the observation that under field conditions sclerotia of $S$. rolfsii are formed on the surface of, rather than inside the infected plant tissue (Aycock, 1966). Sclerotium production by the aerial mycelium requires oxygen concentrations higher than $15 \%$ which are never reached inside agar or liquid media, yet hyphal growth is not inhibited at lower oxygen concentrations (Griffin \& Nair, 1968). Our results indicate that both submerged and aerial mycelia participate in sclerotium production: the site of sclerotium formation is restricted to the aerial mycelium and the initiation of the process is regulated by the submerged mycelium. The capacity to induce sclerotia develops in the submerged mycelium within $72 \mathrm{~h}$ and declines with further incubation.

These results are consistent with working hypotheses suggested by other authors to explain the mechanism involved in induction of sclerotium formation by $S$. rolfsii. Thus, Wheeler \& Waller (1965) claimed that sclerotial initiation and growth of vegetative mycelium competed with each other for metabolites essential for sclerotium production. Goujon (1970) proposed that a 'morphogenetic factor', probably a protein, must reach a critical concentration inside the hyphae. Kritzman et al. (1976) suggested that formation of sclerotia required an increased supply of carbohydrates and energy which were mainly provided by the glyoxylate pathway. In none of these studies, however, were the physiological differences between the submerged and the aerial mycelia and their possible role in sclerotial initiation considered.

The relationship between the age of the submerged mycelium and its potential to produce sclerotial initials suggests that metabolites or enzymes formed in the submerged growth phase play a role in the aerobic growth phase. These factors are probably transported to the aerial mycelium where they induce sclerotium formation.

This research was supported by a grant from Der Niedersachsische Minister für Wissenschaft und Kunst, West Germany.

\section{REFERENCES}

Aycock, R. (1966). Stem rot and other diseases caused by Sclerotium rolfsii. North Carolina Agricultural Experiment Station, Technical Bulletin no. 174.

Chet, I. \& Henis, Y. (1972). The response of two types of Sclerotium rolfsii to factors affecting sclerotium formation. Journal of General Microbiology 73, 483-486.
Chet, I., Henis, Y. \& Mitchell, R. (1966). The morphogenetic effect of sulphur-containing amino acids, glutathione and iodoacetic acid on Sclerotium rolfsii Sacc. Journal of General Microbiology 45, 541-546.

Goujon, M. (1970). Méchanismes physiologiques de la formation de sclérotes chez le Corticium rolfsii. Physiologie Végétale 8, 349-360. 
GrifFIN, D. M. \& NaIR, N. G. (1968). Growth of Sclerotium rolfsii at different concentrations of oxygen and carbon dioxide. Journal of Experimental Botany 19, 812-816.

Henis, Y., Chet, I. \& Avizohar-Hershenzon, Z. (1965). Nutritional and mechanical factors involved in mycelium growth and production of sclerotia by Sclerotium rolfsii in artificial medium and amended soil. Phytopathology 55, 87-91.

Kritzman, G., Okon, Y., Chet, I. \& Henis, Y. (1976). Metabolism of L-threonine and its relationship to sclerotium formation in Sclerotium rolfsii. Journal of General Microbiology 95, 78-86.

KritzMan, G., Chet, I. \& HeNIS, Y. (1979). Isolation of extracellular polysaccharides from Sclerotium rolfsii. Canadian Journal of Botany 57, 1855-1859.

OKon, Y., Chet, I. \& HenIs, Y. (1972). Lactose induced synchronous sclerotium formation in Sclerotium rolfsii and its inhibition by ethanol. Journal of General Microbiology 71, 465-470.

OKon, Y., Chet, I. \& HeNIS, Y. (1973). Effects of lactose, ethanol and cycloheximide on the trans- location pattern of radioactive compounds and on sclerotium formation in Sclerotium rolfsii. Journal of General Microbiology 74, 251-258.

Okon, Y., Chet, I., Kislev, N. \& Henis, Y. (1974). Effect of lactose on soluble-glucan production and on the ultrastructure of Sclerotium rolfsii Sacc. grown in submerged culture. Journal of General Microbiology 81, 145-149.

Townsend, B. B. \& Willetts, H. J. (1954). The development of sclerotia of certain fungi. Transactions of the British Myocological Society 37, 213-221.

WheEler, B. E. J. \& W Aller, J. M. (1965). The production of sclerotia by Sclerotium rolfsii. II. The relationship between mycelial growth and initiation of sclerotia. Transactions of the British Mycological Society 48, 303-314.

Zweck, S., HuttermanN, A. \& Chet, I. (1978). A convenient method for preparing inocula of homogenized mycelia. Experimental Mycology 2, 377378. 